\title{
Comparison of Locally Sourced Pericardium and Other Conventional Patch Graft Materials in a Glaucoma Drainage Device Surgery
}

\author{
Shruti Aggarwal ${ }^{1}$, Candice Kremer $^{2}$, Stephanie Engelhard ${ }^{3}$, Sandra Johnson ${ }^{4}$
}

\begin{abstract}
Purpose: Our study aimed to compare the outcomes and costs of various patch graft materials used in the setting of glaucoma drainage device (GDD) surgeries: conventional Tutoplast ${ }^{\oplus}$ pericardium (TP), locally-obtained Lifenet ${ }^{\oplus}$ pericardium (LP), and tissue-banked corneal (CP) and scleral (SP) patches.

Design: Retrospective observational study.

Subjects: One hundred and ninety-five eyes of 185 patients who underwent glaucoma device surgery with patch grafts were included.

Materials and methods: Patient records were reviewed for demographics and surgical data including age at the time of GDD surgery, race, sex, eye, history of diabetes or immunologic disease, glaucoma diagnosis, length of follow-up, pre- and postoperative intraocular pressure (IOP), type and location of GDD, patch type, and tube-related complications.

Main outcome measures: The primary outcome measures were rates of patch graft-related complications including conjunctival dehiscence with and without tube exposure. Secondary outcome measures were IOP control achieved and cost of patch graft materials.

Results: Mean follow-up for all eyes was 17.1 months. Overall, conjunctival dehiscence without tube exposure occurred in four eyes (2.1\%); tube exposure was seen in six eyes (3.1\%). The mean time to exposure was 3.3 months (range 1-8 months). The rate of tube exposure was $2.3 \%$ of eyes with TP grafts, $10.7 \%$ of eyes with CP grafts, $2.8 \%$ of eyes with SP grafts, and $0 \%$ of eyes with LP grafts. There was no significant difference in rates of tube exposure rates by graft material $(p=0.26)$. Multivariate logistic regression analysis with adjustment for patch type, age, sex, implant type, and location revealed no significant risk factors for tube exposure. Univariate logistic regression was then performed on the same risk factors as well as diabetes, prior and concurrent ocular surgery, and showed no significance.

Conclusion: Our preliminary, short-term results show that locally sourced patch graft material can be a cost-effective alternative to traditionally used patch grafts without an increase in tube exposure rates. To further determine the efficacy of the different patch graft materials, longer-term comparative prospective trials are needed. Longer prospective studies are needed to compare the long-term safety and rate of tube exposures in these locally obtained patch graft materials.

Keywords: Anti-glaucomatous valve, Corneal patch graft, Glaucoma drainage devices, Glaucoma surgery, Sclera patch graft. Journal of Current Glaucoma Practice (2021): 10.5005/jp-journals-10078-1294
\end{abstract}

\section{INTRODUCTION}

Glaucoma drainage device (GDD) implantation is a well-established surgery to lower intraocular pressure (IOP) by diverting aqueous humor from the anterior chamber to an external reservoir. Although the concept of GDDs was introduced over a century ago in 1906, they were popularized in 1976 by Molteno et al. ${ }^{2}$ Since then, both the device design and surgical techniques have evolved to improve clinical outcomes and decrease complications. ${ }^{3,4}$ Traditionally, these surgeries were performed after failed trabeculectomy or in complex glaucomas such as neovascular, uveitic, and traumatic. ${ }^{4}$ With studies showing good long-term IOP lowering, possibly less postoperative complications vs traditional filtering procedures, and success in pediatric and complicated glaucomas, the utilization of GDD surgery, both as primary procedure and as second surgery has increased significantly over the past decade. ${ }^{5-7}$

A GDD is composed of two components-a plate and a tube. The tube runs along the sclera to enter the anterior chamber. Direct contact between the tube and conjunctiva can lead to conjunctival erosion over time. ${ }^{8}$ The subsequent tube exposure is a serious complication as it can lead to endophthalmitis. ${ }^{9}$ Biologic patch grafts are used to cover the tube and prevent its erosion through
${ }^{1}$ Department of Ophthalmology, University of Virginia, Charlottesville, Virginia, USA; Katzen Eye Institute, Baltimore, Maryland, USA

2,3 Department of Ophthalmology, University of Virginia, Charlottesville, Virginia, USA

${ }^{4}$ Mason Eye, University of Missouri, Columbia, Missouri, USA

Corresponding Author: Sandra Johnson, Mason Eye, University of Missouri, Columbia, Missouri, USA, Phone: +1 813-974-5228, e-mail: smjeyes@gmail.com

How to cite this article: Aggarwal S, Kremer C, Engelhard S, et al. Comparison of Locally Sourced Pericardium and Other Conventional Patch Graft Materials in a Glaucoma Drainage Device Surgery. J Curr Glaucoma Pract 2021;15(1):14-18.

Source of support: Nil

Conflict of interest: None

the conjunctiva. Various patch graft materials have been used, such as donor sclera, cornea, dura mater, and pericardium. Each patch graft material is associated with risks and benefits when evaluated by availability, price, and efficacy. The decision to use a particular

(0) Jaypee Brothers Medical Publishers. 2021 Open Access This article is distributed under the terms of the Creative Commons Attribution 4.0 International License (https://creativecommons.org/licenses/by-nc/4.0/), which permits unrestricted use, distribution, and non-commercial reproduction in any medium, provided you give appropriate credit to the original author(s) and the source, provide a link to the Creative Commons license, and indicate if changes were made. The Creative Commons Public Domain Dedication waiver (http://creativecommons.org/publicdomain/zero/1.0/) applies to the data made available in this article, unless otherwise stated. 
patch graft may be based on surgeon preference, patch thickness, availability, cosmesis, and cost. ${ }^{10}$

In January 2015, the Center for Medicare and Medicaid Service bundled the patch graft component with the glaucoma implant code, thereby making it important to include price and availability considerations when evaluating the utility of patch graft materials. ${ }^{11}$

With healthcare costs becoming a growing concern, it is crucial for healthcare providers to keep the quality of care high while reducing costs when possible. As members of an accountable care organization (ACO), physicians at our institution aim to look for cost-effective measures. We use a pericardium patch graft from a local tissue company, which has a lower cost relative to other patch graft materials.

Our study aimed to compare the preliminary outcomes of locally sourced pericardial patch graft relative to other conventional patch grafts including tissue-banked corneal and scleral patches and pericardium products from a national tissue bank in the setting of GDD surgeries.

\section{Materials and Methods}

This was a retrospective, observational study of patients who were implanted with GDDs over 4 years (September 2102 to November 2016) at a single center, the Department of Ophthalmology at the University of Virginia. The study was approved by the institutional review board of the University of Virginia and was conducted in accordance with the principles of the Declaration of Helsinki. The requirement for written informed consent was waived due to the retrospective nature of the study.

The inclusion criterion included age over 18 years undergoing GDD surgery with patch graft with a minimum of 6 months follow-up. One hundred and ninety-five eyes of 185 patients were identified from the electronic medical record. Drainage devices included 132 Ahmed Glaucoma Valves (New World Medicine, Inc., Rancho Cucamonga, CA, USA) and 63 Baerveldt implants (Advanced Medical Optics, Inc., Santa Ana, CA, USA). Ahmed glaucoma valves in the study included Model FP-7 $(n=127)$ and Model M4 $(n=5)$. All implanted Baerveldt implants were the 350 model. Eyes were categorized by the type of patch graft used. Patch graft materials included conventional irradiated Tutoplast ${ }^{\circledR}$ pericardium (TP) (IOP Ophthalmics, Costa Mesa, CA, USA), locally obtained LifeNet ${ }^{\oplus}$ pericardium (LP) (LifeNet Health ${ }^{\oplus}$, Virginia Beach, VA, USA), tissuebanked corneal patches (CP), and scleral patches (SP). Figure 1 shows the LP in place 1-year postoperatively. All the surgeries using LP were done by a single surgeon using a limbus-based approach.

Patient records were reviewed for demographic information and surgical data including age at the time of GDD surgery, race sex, eye, diabetes history, immunologic disease history, glaucoma diagnosis, length of follow-up, pre- and postoperative IOP, type and location of GDD, conjunctival patch type, and complications including tube exposure and conjunctival dehiscence. The primary outcome measures were rate and risk factors for patch graft-related complications including conjunctival dehiscence with and without tube exposure. Conjunctival dehiscence was described as any breakdown of the conjunctiva over the tube or plate or limbus. Secondary outcome measures were IOP control achieved and cost of patch graft materials.

Data are reported as mean \pm standard deviation. Descriptive statistics were used to describe the data. A comparison of the rates of exposure was analyzed using the ANOVA test. Univariate analysis was performed to assess if various factors such as age, sex, type of implant, the location of implant, diabetes, concurrent, and prior ocular surgeries were associated with an increased exposure rate. A multivariate logistic regression model adjusted for each of the above-mentioned factors was used to assess the association between patch type and exposure rate. Significance was set at $p \leq 0.05$.

\section{Results}

Demographics and patient characteristics are shown in Table 1. One hundred and ninety-five eyes of 185 patients were included in the study. Mean age was $64.1 \pm 16.5$ years ( $54.9 \%$ male; $45.1 \%$ female). Of 195 eyes undergoing GDD surgeries, the patch graft materials were TP $(n=43,22.1 \%), \mathrm{LP}(n=53,27.2 \%), \mathrm{CP}(n=28,14.4 \%)$, and SP $(n=71,36.4 \%)$. Mean preoperative IOP across all groups was $28.4 \pm$ $12.6 \mathrm{~mm} \mathrm{Hg}$, while mean postoperative IOP was $14.4 \pm 6.1 \mathrm{~mm} \mathrm{Hg}$, representing a significant IOP decrease $(p=0.0)$. Mean follow-up for all eyes was 17.1 months (range 6-30 months), with no significant difference in follow-up times among the different groups.

Overall, conjunctival dehiscence without tube exposure occurred in four eyes (2.1\%). There were six tube exposures (3.1\%). Other tube-related complications were tube malpositioning (1.0\%) requiring repositioning and one tube blockage $(0.5 \%)$ requiring tube revision. Patient characteristics, surgical indications and characteristics, and complications by patch graft material are shown in Table 2.

Among eyes with tube exposure, the mean age was 68.8 years (range 51-86 years). Four of six tube exposures occurred in open-angle glaucoma, and one each occurred in neovascular and pseudoexfoliation glaucoma. Mean follow-up in these six cases was 21 months. The mean time to exposure was 3.3 months (range 1-8 months). Four exposures occurred in Ahmed FP7 implants, and two occurred in Baerveldt 350 implants. Two of six exposures occurred in eyes with inferiorly located implants.

Tube exposure occurred in $2.3 \%$ of eyes with TP grafts, $10.7 \%$ of eyes with CP grafts, $2.8 \%$ of eyes with SP grafts, and $0 \%$ of eyes with LP grafts. Tube exposure rate by patch graft material is shown in Figure 2. ANOVA showed that there was no significant difference in rates of tube exposure rates by graft material used ( $\left.p=0.26, R^{2}-0.02\right)$. Multivariate logistic regression analysis with adjustment for patch type, age, sex, implant type, and location revealed no significant risk factors for tube exposure. Univariate logistic regression was then performed on the same risk factors as well as diabetes, prior and concurrent ocular surgery, and continued to show no significance.

\section{Discussion}

Complications associated with the GDD surgery as reported by the American Academy of Ophthalmology, include hypotony both in the immediate and late postsurgical period, high IOP and clinical failure with excessive capsular fibrosis around the plate and tube, tube-related complications-malposition, blockage, and exposure; and conjunctival retraction, dehiscence, and scarring. ${ }^{12,13}$ Tube exposure is a well-known complication, which prompts urgent surgical intervention. It can lead to symptoms of ocular irritation, focal injection, pain, and light sensitivity. It leads to hypotony, inflammation, corneal decompensation, and infection leading to endophthalmitis. ${ }^{9,14,15}$

The reported rate of tube exposure is very variable and ranges from 2 to $7 \%$; with the mean time to tube exposure ranging from 


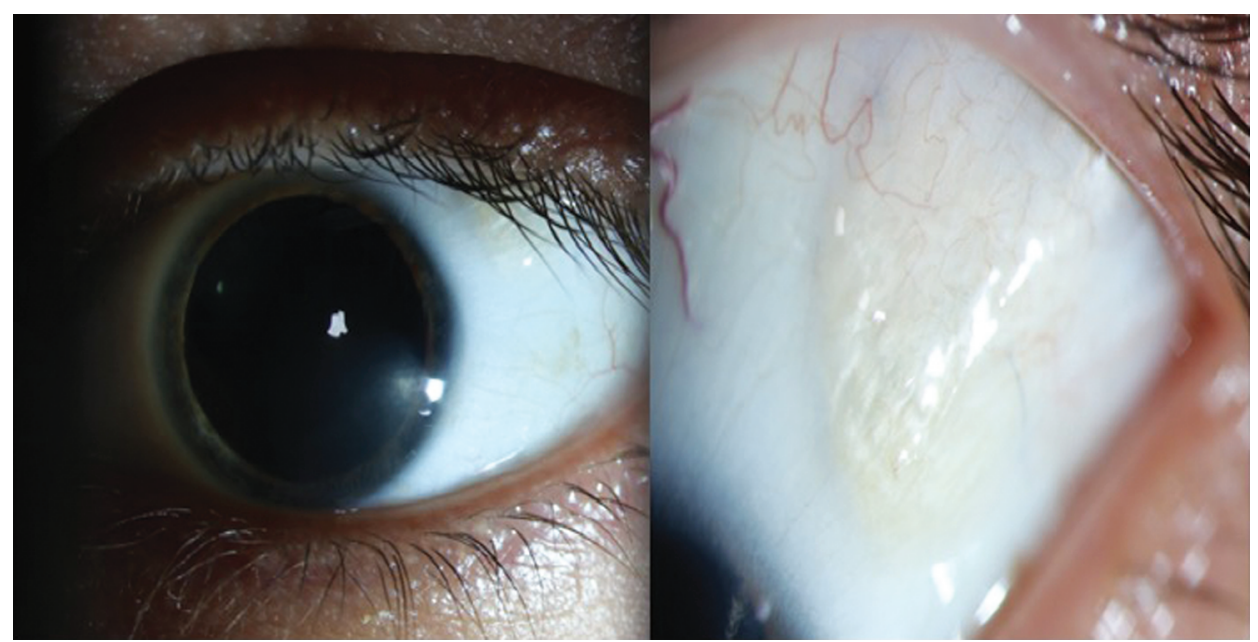

Fig. 1: Slit lamp biomicroscopy photograph showing LifeNet pericardium patch graft in place 1 year postoperatively

Table 1: Details of demographics and patient characteristics

\begin{tabular}{|c|c|c|c|c|c|}
\hline $\begin{array}{l}\text { Demographics and } \\
\text { patient characteristics }\end{array}$ & $\begin{array}{l}\text { Tutoplast }{ }^{\oplus} \text { pericardium } \\
\text { ( } n=43 \text { eyes) }(22.1 \%)\end{array}$ & $\begin{array}{l}\text { Tissue-banked corneal patch } \\
\text { ( } n=28 \text { eyes) }(14.4 \%)\end{array}$ & $\begin{array}{l}\text { Scleral patch }(n=71 \\
\text { eyes) }(36.4 \%)\end{array}$ & $\begin{array}{l}\text { Lifenet }^{\oplus} \text { pericardium } \\
(n=53 \text { eyes) }(27.2 \%)\end{array}$ & $\begin{array}{l}\text { All }(n=195 \text { eyes }) \\
(100 \%)\end{array}$ \\
\hline \multicolumn{6}{|l|}{ Age (years) } \\
\hline Mean \pm SD & $59.4 \pm 14.5$ & $57.8 \pm 16.2$ & $73.0 \pm 13.3$ & $59.3 \pm 17.4$ & $64.1 \pm 16.5$ \\
\hline \multicolumn{6}{|l|}{ Sex (\%) } \\
\hline Male & $26(60.5)$ & $19(67.9)$ & $36(50.7)$ & $27(50.9)$ & $107(54.9)$ \\
\hline Female & $17(39.5)$ & $9(32.1)$ & $35(49.3)$ & $26(49.1)$ & $88(45.1)$ \\
\hline \multicolumn{6}{|l|}{ Ethnicity } \\
\hline African American & $16(37.2)$ & $9(32.1)$ & $18(25.4)$ & $16(30.2)$ & $58(29.7)$ \\
\hline Caucasian & $20(46.5)$ & $15(53.6)$ & $49(69.0)$ & $29(54.7)$ & $113(57.9)$ \\
\hline Hispanic & $3(7.0)$ & $0(0)$ & $1(1.4)$ & $5(9.4)$ & $9(4.6)$ \\
\hline Other & $4(9.3)$ & $4(14.3)$ & $3(4.2)$ & $3(5.7)$ & $15(7.7)$ \\
\hline \multicolumn{6}{|l|}{ Eye } \\
\hline Right & $27(62.8)$ & $11(39.3)$ & $31(43.6)$ & $26(49.1)$ & $95(48.7)$ \\
\hline Left & $16(37.2)$ & $17(60.7)$ & $40(56.3)$ & $27(50.9)$ & $100(51.3)$ \\
\hline
\end{tabular}

SD, standard deviation

as short as 4 weeks to up to 5 years after surgery. ${ }^{16-21}$ In a large meta-analysis study, the incidence of tube exposure was reported to be $2.0 \pm 2.6 \%$, with an average exposure rate per month of $0.09 \pm 0.14 \% .{ }^{22}$ Netland et al. ${ }^{23}$ reported tube exposure at a mean of $1.43 \pm 1.5$ years. Our data agree with the literature; the tube exposure rate in our patient population was $3.1 \%$, the rate of conjunctival dehiscence without tube exposure was $2.1 \%$. The mean onset of tube exposure was at 3.3 months of follow-up, the range being 1-8 months.

Various mechanisms for tube exposure have been postulated, including both high-grade and low-grade inflammation leading to rapid and slow gradual tube exposure, respectively. ${ }^{20}$ Direct contact between tube and conjunctiva is shown to be an important mechanism for conjunctival erosion. ${ }^{8}$ In an attempt to decrease the contact and prevent tube erosion while reenforcing overlying conjunctiva, Freedman described the successful use of fullthickness, glycerin preserved, full-thickness scleral patch graft in 16 patients undergoing GDD surgery in $1987 .{ }^{24}$ Since then, use of many different patch graft materials has been described. ${ }^{25}$ Commonly used commercially available grafts include sclera; partial and fullthickness cornea, fascia lata, and pericardium.
We reviewed the outcomes of the patch graft materials used for GDD surgery at our institution-banked donor sclera, donor cornea, Tutoplast pericardium, and locally sourced pericardium and found no significant difference in the tube exposure rate among the four groups. Multiple other studies have also compared the rate of tube exposure using the different patch graft materials. Muir et al. ${ }^{26}$ compared eye bank sclera, Tutoplast sclera, and pericardium. Smith et al. ${ }^{20}$ compared eye bank sclera, dura, and pericardium; while Zalta ${ }^{27}$ looked at erosion rates in donor dura and sclera. None of those studies found a significant increase in tube exposure in any particular type of patch graft material.

Considerations while choosing appropriate graft are the location of the implant, thickness, size, longevity of graft material, ease of manipulation, past patch erosions, and cosmetic outcomes..$^{10,25}$ Cost of the graft is important to consider. The cost of the patch graft depends on the type of tissue, harvesting and processing costs, and shipping costs. At our institute, the average cost of these grafts is $\$ 295-\$ 415$ for banked cornea, $\$ 250$ for banked sclera, and $\$ 275$ for Tutoplast pericardium. As a part of being an ACO, we have tried a more cost-effective alternative to conventional patch grafts. LifeNet ${ }^{\circledast}$ pericardium (LP) (LifeNet Health ${ }^{\circledast}$, Virginia 


\begin{tabular}{|c|c|c|c|c|c|}
\hline & $\begin{array}{l}\text { Tutoplast }{ }^{\oplus} \text { pericardium } \\
\text { ( } n=43 \text { eyes) }(22.1 \%)\end{array}$ & $\begin{array}{l}\text { Tissue-banked corneal } \\
\text { patch ( } n=28 \text { eyes) }(14.4 \%)\end{array}$ & $\begin{array}{l}\text { Scleral patch }(n=71 \\
\text { eyes) }(36.4 \%)\end{array}$ & $\begin{array}{l}\text { Lifenet }{ }^{\oplus} \text { pericardium } \\
\text { ( } n=53 \text { eyes) }(27.2 \%)\end{array}$ & $\begin{array}{l}\text { All }(n=195 \text { eyes }) \\
(100 \%)\end{array}$ \\
\hline \multicolumn{6}{|l|}{ Patient characteristics } \\
\hline \multicolumn{6}{|l|}{ Diabetes } \\
\hline Yes & $17(39.5)$ & $12(42.9)$ & $10(14.1)$ & $25(47.2)$ & $64(32.8)$ \\
\hline No & $26(60.5)$ & $16(57.1)$ & $61(85.9)$ & $28(52.8)$ & $131(67.2)$ \\
\hline \multicolumn{6}{|l|}{ Prior surgeries } \\
\hline Scleral buckle & $2(4.7)$ & $1(3.6)$ & $2(2.8)$ & $4(7.5)$ & $9(4.6)$ \\
\hline Trabeculectomy & $5(11.6)$ & $11(39.3)$ & $36(50.7)$ & $10(18.9)$ & $62(31.8)$ \\
\hline \multicolumn{6}{|c|}{ Indications for surgery (glaucoma diagnosis) } \\
\hline Open-angle & $12(27.9)$ & $10(35.7)$ & $47(66.2)$ & $21(39.6)$ & $90(46.2)$ \\
\hline Neovascular & $11(25.6)$ & $5(17.9)$ & $2(2.8)$ & $18(34.0)$ & $36(18.5)$ \\
\hline Angle-closure & $4(9.3)$ & $2(7.1)$ & $7(9.9)$ & $3(5.7)$ & $16(8.2)$ \\
\hline Traumatic & $4(9.3)$ & $2(7.1)$ & $2(2.8)$ & $1(1.9)$ & $9(4.6)$ \\
\hline Uveitic & $10(23.3)$ & $3(10.7)$ & $0(0)$ & $5(9.4)$ & $18(9.2)$ \\
\hline Pseudoexfoliation & $2(4.7)$ & $0(0)$ & $11(15.5)$ & $0(0)$ & $13(6.7)$ \\
\hline Congenital & $0(0)$ & $5(17.9)$ & $2(2.8)$ & $0(0)$ & 7 (3.6) \\
\hline Aphakic & $0(0)$ & $1(3.6)$ & $0(0)$ & $5(9.4)$ & $6(3.1)$ \\
\hline \multicolumn{6}{|l|}{ Surgical characteristics } \\
\hline \multicolumn{6}{|c|}{ Glaucoma implant type (\%) } \\
\hline Ahmed FP7 & $41(95.3)$ & $26(92.9)$ & $8(11.3)$ & $52(98.1)$ & $127(65.1)$ \\
\hline Ahmed M4 & $2(4.7)$ & $2(7.1)$ & $0(0)$ & $1(1.9)$ & $5(2.6)$ \\
\hline Baerveldt & $0(0)$ & $0(0)$ & $63(88.7)$ & $0(0)$ & $63(32.3)$ \\
\hline \multicolumn{6}{|l|}{ Implant location (\%) } \\
\hline Superior & $42(97.7)$ & $23(82.1)$ & $61(85.9)$ & $50(94.3)$ & $176(90.3)$ \\
\hline Inferior & $1(2.3)$ & $5(17.9)$ & $10(14.1)$ & $3(5.7)$ & $19(9.7)$ \\
\hline \multicolumn{6}{|l|}{ Complications } \\
\hline \multicolumn{6}{|l|}{ Tube exposure } \\
\hline Yes & $1(2.3)$ & $3(10.7)$ & $2(2.8)$ & $0(0)$ & $6(3.1)$ \\
\hline No & $42(97.7)$ & $25(89.3)$ & $69(97.2)$ & $53(100)$ & 189 (96.9) \\
\hline \multicolumn{6}{|c|}{ Conjunctival dehiscence } \\
\hline Yes & $2(4.7)$ & $0(0)$ & $1(1.4)$ & $1(1.9)$ & $4(2.1)$ \\
\hline No & $41(95.3)$ & $28(100)$ & $70(98.6)$ & $52(98.1)$ & $191(97.9)$ \\
\hline
\end{tabular}

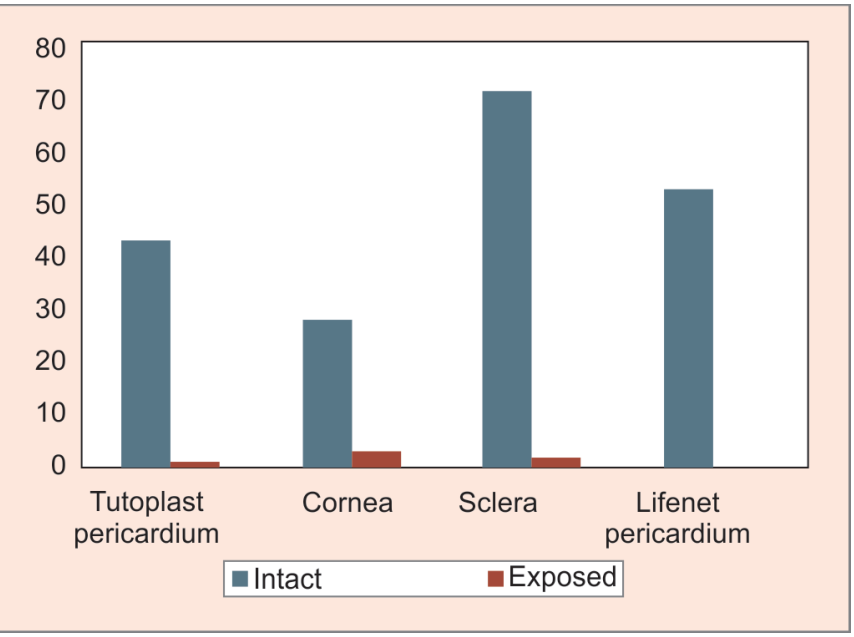

Fig. 2: Bar graph showing tube exposure in the different patch graft groups
Beach, VA, USA) is a pericardial patch graft obtained from a local company. The average cost of LP is $\$ 105.75$. Consideration of cost has become a prominent issue given the rising cost of health care and the recent changes in the billing codes for GDD surgery. What used to be two separate codes-GDD implantation and scleral re-enforcement with patch graft, is now a bundled payment code. ${ }^{11}$

In addition to assessing whether the type of patch graft used influenced tube exposure, we also assessed other risk factors that may be associated with increased tube exposure. In the literature, various risk factors for tube exposure have been identified; the most important being younger age at the time of surgery, ${ }_{1}^{23}$ ocular inflammation, ${ }^{23}$ concomitant ocular surgery, ${ }^{28}$ number or prior ocular surgeries, ${ }^{16}$ and inferior quadrant positing of the implant. ${ }^{29,30}$ Role of systemic conditions such as diabetes, hypertension, and rheumatologic conditions remains controversial. ${ }^{23,26,27,31}$ In our study, we performed univariate logistic regression analysis for factors including age, sex, type of implant, location of implant, diabetes, concurrent and prior ocular surgeries to assess for association with tube exposure. We did not find any of these 
associated with an increased rate of tube exposure in the number of cases reviewed. This may be due to the small number of patients with tube exposure making it not possible to establish a statistical significance; a much larger number of patients with exposure would help to establish any significant risk factors.

While our study shows promising preliminary results on the use of the local tissue bank graft (LP), it does have limitations. This is a retrospective study and suffers from the limitations of a retrospective chart review. Also, the data are accumulated from the different surgeons and hence there is a possible bias based on surgeon technique, tissue handling, and patient population. We have follow-up data for at least 6 months; however, as complications have been shown as late as 5 years after surgery, we need a longer follow-up time to determine the long-term safety of locally sourced pericardial tissue vs other patch graft materials. Another important consideration is that while comparative, our study is not a noninferiority study. Given an incidence rate of $2-5 \%$ of tube exposure rate reported in the literature and our results, power analysis shows that for a power of $80 \%$, alpha of 0.05 , assuming no $>5 \%$ exposure rate over the baseline $5 \%$ exposure rate, we would need a minimum of 382 patients in each arm of the patch graft type group, which is challenging in a single institution-based study.

To conclude, our preliminary study shows that locally sourced patch graft material is a cost-effective alternative to commercial patch grafts with good short-term results without an increased rate of complications. Further, prospective studies with longer followups and larger sample sizes are needed to further determine the comparative efficacy of different patch materials.

\section{References}

1. Rollett $\mathrm{M}$, Moreau $\mathrm{M}$. Le drainage au crin de la chambre anterieure contre I'hypertonie et la douleur. Rev Gen Ophtalmol 1907;26:289292.

2. Molteno AC, Straughan JL, Ancker E. Long tube implants in the management of glaucoma. S Afr Med J 1976;50(27):1062-1066.

3. Coleman AL, Wilson MR, Tam M, et al. Initial clinical experience with the Ahmed glaucoma valve implant--correction. Am J Ophthalmol 1995;120(5):684. DOI: 10.1016/s0002-9394(14)72225-1.

4. Patel S, Pasquale LR. Glaucoma drainage devices: a review of the past, present, and future. Semin Ophthalmol 2010;25(5-6):265-270. DOI: 10.3109/08820538.2010.518840.

5. Gedde SJ, Schiffman JC, Feuer WJ, et al. Treatment outcomes in the tube versus trabeculectomy (TVT) study after five years of follow-up. Am J Ophthalmol 2012;153(5):789-803.e2. DOI: 10.1016/j. ajo.2011.10.026.

6. Gedde SJ, Singh K, Schiffman JC, et al. The tube versus trabeculectomy study: interpretation of results and application to clinical practice. Curr Opin Ophthalmol 2012;23(2):118-126. DOI: 10.1097/ ICU.0b013e32834ff2d1.

7. http://www.ophthalmologymanagement.com/issues/2015/ february-2015/glaucoma-coding-2015-brings-changes.

8. Tamcelik N, Ozkok A, Sarıcı AM, et al. Tenon advancement and duplication technique to prevent postoperative Ahmed valve tube exposure in patients with refractory glaucoma. Jpn J Ophthalmol 2013;57(4):359-364. DOI: 10.1007/s10384-013-0249-5.

9. Gedde SJ, Scott IU, Tabandeh H, et al. Late endophthalmitis associated with glaucoma drainage implants. Ophthalmology 2001;108(7): 1323-1327. DOI: 10.1016/s0161-6420(01)00598-x.

10. Lind JT, Shute TS, Sheybani A. Patch graft materials for glaucoma tube implants. Curr Opin Ophthalmol 2017;28(2):194-198. DOI: 10.1097/ ICU.0000000000000347.
11. http://ophthalmologytimes.modernmedicine.com/ ophthalmologytimes/news/cpt-coding-glaucoma-surgeryreporting-undergoes-changes?page $=$ full.

12. Minckler DS, Francis BA, Hodapp EA, et al. Aqueous shunts in glaucoma: a report by the American Academy of Ophthalmology. Ophthalmology 2008;115(6):1089-1098. DOI: 10.1016/j. ophtha.2008.03.031.

13. Riva I, Roberti G, Oddone F, et al. Ahmed glaucoma valve implant: surgical technique and complications. Clin Ophthalmol 2017;11:357367. DOI: $10.2147 /$ OPTH.S104220.

14. Al-Torbak AA, Al-Shahwan S, Al-Jadaan I, et al. Endophthalmitis associated with the Ahmed glaucoma valve implant. $\mathrm{Br} J$ Ophthalmol 2005;89(4):454-458. DOI: 10.1136/bjo.2004.049015.

15. Wentzloff JN, Grosskreutz CL, Pasquale LR, et al. Endophthalmitis after glaucoma drainage implant surgery. Int Ophthalmol Clin 2007;47(2):109-115. DOI: 10.1097/IIO.0b013e318037766a.

16. Byun YS, Lee NY, Park CK. Risk factors of implant exposure outside the conjunctiva after Ahmed glaucoma valve implantation. Jpn J Ophthalmol 2009;53(2):114-119. DOI: 10.1007/s10384-008-0630-y.

17. Chen $H$, Zhang SX, Liu L, et al. Intermediate-term and long-term clinical evaluation of the Ahmed glaucoma valve implantation. Zhonghua Yan Ke Za Zhi 2005;41(9):796-802.

18. Montañez FJ, Laso E, Suñer M, et al. Ahmed drainage device implant. Our experience between 1995 and 2003. Arch Soc Esp Oftalmol 2005;80(4):239-244. DOI: 10.4321/s0365-66912005000400007.

19. Siegner SW, Netland PA, Urban RC, et al. Clinical experience with the Baerveldt glaucoma drainage implant. Ophthalmology 1995;102(9):1298-1307. DOI: 10.1016/s0161-6420(95)30871-8.

20. Smith MF, Doyle JW, Ticrney JW. A comparison of glaucoma drainage implant tube coverage. J Glaucoma 2002;11(2):143-147. DOI: 10.1097/00061198-200204000-00010.

21. Wishart PK, Choudhary A, Wong D. Ahmed glaucoma valves in refractory glaucoma: a 7-year audit. Br J Ophthalmol 2010;94(9): 1174-1179. DOI: 10.1136/bjo.2009.165357.

22. Stewart WC, Kristoffersen CJ, Demos CM, et al. Incidence of conjunctival exposure following drainage device implantation in patients with glaucoma. Eur J Ophthalmol 2010;20(1):124-130. DOI: 10.1177/112067211002000117.

23. Netland $P$, Chaku $M$, Ishida $K$, et al. Risk factors for tube exposure as a late complication of glaucoma drainage implant surgery. Clin Ophthalmol 2016;10:547-553. DOI: 10.2147/OPTH.S104029.

24. Freedman J. Scleral patch grafts with molteno setons. Ophthalmic Surg 1987;18(7):532-534.

25. Thakur $S$, Ichhpujani $P$, Kumar $S$. Grafts in glaucoma surgery: a review of the literature. Asia Pac J Ophthalmol (Phila) 2017;6(5):469-476. DOI: 10.22608/APO.2016123.

26. Muir KW, Lim A, Stinnett S, et al. Risk factors for exposure of glaucoma drainage devices: a retrospective observational study. BMJ Open 2014;4(5):e004560. DOI: 10.1136/bmjopen-2013-004560.

27. Zalta AH. Long-term experience of patch graft failure after Ahmed glaucoma valve(R) surgery using donor dura and sclera allografts. Ophthalmic Surg Lasers Imaging 2012;43(5):408-415. DOI: 10.3928/15428877-20120517-01.

28. Trubnik V, Zangalli C, Moster MR, et al. Evaluation of risk factors for glaucoma drainage device-related erosions: a retrospective case-control study. J Glaucoma 2015;24(7):498-502. DOI: 10.1097/ IJG.0000000000000034.

29. Levinson JD, Giangiacomo AL, Beck AD, et al. Glaucoma drainage devices: risk of exposure and infection. Am J Ophthalmol 2015;160(3):516-521.e2. DOI: 10.1016/j.ajo.2015.05.025.

30. Pakravan M, Yazdani S, Shahabi C, et al. Superior versus inferior Ahmed glaucoma valve implantation. Ophthalmology 2009;116(2):208-213. DOI: 10.1016/j.ophtha.2008.09.003.

31. Geffen N, Buys YM, Smith M, et al. Conjunctival complications related to Ahmed glaucoma valve insertion. J Glaucoma 2014;23(2):109-114. DOI: 10.1097/IJG.0b013e31826ab693. 